\title{
O PARTIDO COMUNISTA DO BRASIL E A MILITÂNCIA FEMININA $^{i}$
}

\author{
EL PARTIDO COMUNISTA DE BRASIL Y LA MILITANCIA FEMENINA
}

THE COMMUNIST PARTY OF BRAZIL AND THE FEMALE MILITANCE

DOI: $10.22481 /$ rbba.v10i01.8803

\begin{abstract}
Daniella Ataíde Lôbo Universidade Estadual do Sudoeste da Bahia, Brasil

ID Lattes: http://lattes.cnpq.br/4291815491402879

ORCID: https://orcid.org/0000-0001-8408-8916

Endereço eletrônico: al.daniella@gmailcom

Maria Aparecida Silva de Sousa Universidade Estadual do Sudoeste da Bahia, Brasil

ID Lattes: http://lattes.cnpq.br/1717712438822665 ORCID: https://orcid.org/0000-0002-8498-139X Endereço eletrônico: maria.sousa@uesb.edu.br
\end{abstract}

\begin{abstract}
RESUMO
$\mathrm{O}$ presente artigo busca refletir acerca do silenciamento a que foi destinada a militância feminina no interior do Partido Comunista do Brasil e nas páginas da historiografia produzida por militantes desta organização. Por meio dessa perspectiva, propõe-se pensar como algumas lideranças do PCB elaboraram suas concepções sobre a militância feminina e como rememoraram suas trajetórias políticas. Essencialmente indagamos sobre o esquecimento a que foram relegadas as mulheres militantes por seus companheiros, sobretudo no que diz respeito à memória do partido, na tentativa de problematizar questões ainda não
\end{abstract}




\title{
FEMININA
}

enfocadas por parte da historiografia sobre o movimento operário.

Palavras-Chave: Memória; Militância Feminina; PCB.

\section{RESUMEN}

Este artículo busca reflexionar sobre el silenciamiento al que estaba destinada la militancia femenina dentro del Partido Comunista de Brasil y en las páginas de la historiografía producida por militantes de esta organización. A través de esta perspectiva, piense cómo algunas dirigentes del PCB elaboraron sus concepciones sobre la militancia femenina y cómo recordaron sus trayectorias políticas. Esencialmente, preguntamos por el olvido al que las mujeres activistas fueron relegadas por sus compañeras, especialmente en lo que respecta a la memoria del partido, en un intento de problematizar temas que parte de la historiografía insiste en hacer irrelevantes, secundarios e innecesarios.

Palabras Clave: Memoria; Militancia Femenina; PCB.

\begin{abstract}
This article seeks to reflect on the silencing to which female militancy was destined within the Communist Party of Brazil and on the pages of the historiography produced by militants of this organization. Through this perspective, think about how some leaders of the PCB elaborated their conceptions about the female militancy and how they remembered their political trajectories. Essentially, we asked about the forgetfulness to which women activists were relegated by their companions, especially with regard to the party's memory, in an attempt to problematize issues that part of historiography insists on making irrelevant, secondary and unnecessary.
\end{abstract}

Keywords: Female Militancy; Memory; PCB.

\section{INTRODUÇÃO}

O presente artigo resulta de uma pesquisa mais ampla acerca do silêncio a que foram destinadas as mulheres militantes nas páginas das obras sobre o Partido Comunista do Brasil (PCB) produzidas por militantes desta organização. Nesta perspectiva, propõe-se uma reflexão em torno da memória e das concepções de militância feminina, evidenciando a participação das mulheres militantes no interior do PCB, bem como as diretrizes do Partido e os posicionamentos 


\section{O PARTIDO COMUNISTA DO BRASIL E A MILITÂNCIA FEMININA}

de militantes no que dizia respeito às suas companheiras de lutas. Com base nas análises de Halbwachs (2004) e Pollak (1989; 1992) sobre o campo da memória, busca-se contribuir com os estudos sobre um tema ainda pouco explorado pelos historiadores.

Apesar das dificuldades encontradas pelos limites que lhes eram impostos, a participação feminina pela causa proletária no Brasil sempre foi bastante expressiva, algumas vezes chegando a ser o elemento condutor de greves e paralisações, principalmente no ramo têxtil, onde a mão de obra feminina era preponderante. Tal participação estava, em grande medida, atrelada a reivindicações mais amplas da classe operária, visando, desse modo, a obtenção de direitos imediatos e não a defesa de interesses específicos da mulher trabalhadora. Como observa Maria Valéria Junho Pena,

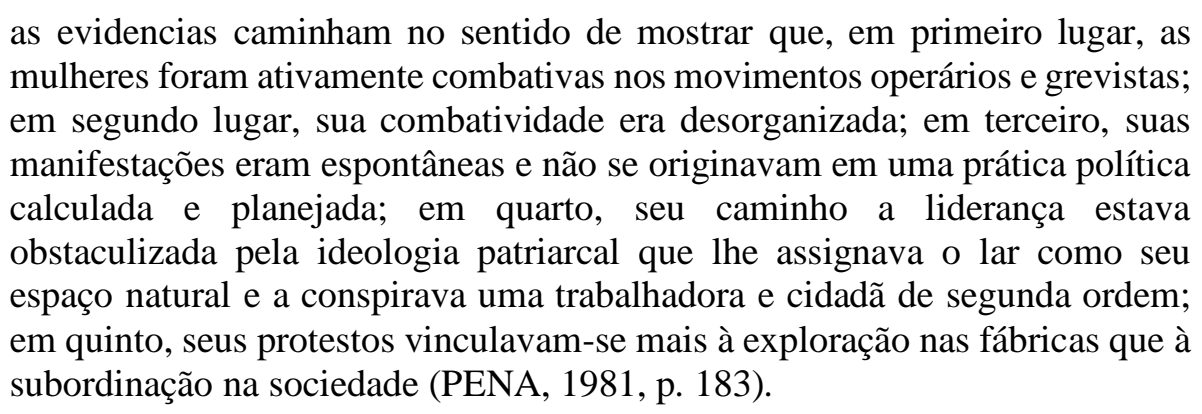

Neste contexto é que se dá uma maior aglutinação das mulheres em organizações e no interior de partidos políticos como o $\mathrm{PCB}^{\mathrm{ii}}$.

Em dado momento, em virtude do crescimento e notoriedade, o Partido Comunista do Brasil passa a dedicar maior atenção às reivindicações femininas, voltando seus olhares às organizações compostas por elas e discutindo suas pautas, porém ainda de forma muito tensa e a contragosto. $\mathrm{O}$ partido entendia a participação feminina e sua militância de forma limitada e pontual, o interesse em alargar suas fileiras e construir um partido de massas com bases sólidas, inicialmente, era um dos maiores objetivos dos dirigentes do PCB.

Parte significativa da historiografia brasileira debruçou-se sobre a história do Partido Comunista do Brasil, todavia, no que se refere a participação das mulheres na organização, ainda existem lacunas a serem preenchidas. Parte dos estudos realizadosiii que discutem a inserção da mulher no partido centram suas análises ao período em que este se encontrava na legalidade, entre os anos de 1945 e 1947, quando, motivados pela urgência em alargar suas fileiras e se consolidar como partido de massa há uma preocupação maior tanto em inserir nas discussões as questões referentes às mulheres, quanto à criação de órgãos no interior do partido 


\section{O PARTIDO COMUNISTA DO BRASIL E A MILITÂNCIA FEMININA}

voltados às suas necessidades. Poucos são os estudos sobre a trajetória política de algumas personagens femininas que militaram junto ao PCB em seus anos iniciais.

Neste trabalho, discutiremos como os militantes pecebistas se lembraram das mulheres e da sua participação politica no interior do partido, por meio da análise da relação do PCB com as diretrizes da Internacional Comunista, bem como suas concepções próprias sobre a militância feminina. Através da instrumentalização da memória, analisamos de que forma o PCB se configurou como principal quadro social a partir do qual os militantes escreveram as obras que compuseram a história do Partido Comunista do Brasil. Assim, valores, concepções e práticas acerca da marginalização e da subvalorização feminina, vigentes no interior do partido, reproduziam as concepções da sociedade capitalista patriarcal, se constituindo nos marcos sociais a partir dos quais rememoraram a formação do PCB e relegaram a participação das mulheres militantes ao esquecimento

\section{Diretrizes do PCB acerca da militância feminina}

As correntes ideológicas que nortearam o movimento operário durante a Primeira República - como o anarquismo nos anos iniciais difundido principalmente pelo contingente imigrante vindo de toda a Europa e o comunismo - apesar de não se mostrarem dispostos a se posicionar enfaticamente a favor da ruptura da situação de marginalização da mulher e, por vezes, reproduzirem um discurso social vigente que legitimava a subvalorização feminina, contaram em sua composição com a presença de mulheres dispostas a levantar questionamentos sobre sua posição tanto na sociedade quanto no interior das próprias organizações. Também tiveram grande ressonância, mesmo possuindo uma curta trajetória, as associações de mulheres de caráter anarquista e comunista que se organizaram em prol da luta pela emancipação feminina atrelada a um contexto mais amplo de mudança da sociedade capitalista. Dentre elas, a União Feminina do Brasil organizada por militantes vinculadas ao Partido Comunista do Brasil que, logo em sua fundação em 1935, lançou um manifesto com suas premissas:

Não poderíamos continuar indiferentes ante os choques, as tragédias e a miséria que nos cercam. Falharíamos a nós mesmas se não pensássemos em lutar ombro a ombro com os homens, pelos nossos direitos. Qual tem sido até hoje nosso papel no Brasil? Na escola, a opressão dos que querem fazer de nossa inteligência um sabujíssimo. Na fábrica, substituindo o homem com salários menores e menor revolta. No escritório produzindo tanto quanto um homem e recebendo muito menos que ele. No lar, prisioneiras passivas, tudo criando e nada produzindo. Na sociedade, joguetes cheios de deveres, tudo se 
nos exigindo, sem direitos, tudo se nos negando. [...] Lutemos Unidas! E, para essa luta, chamemos todas as mulheres do Brasil. Operárias, intelectuais, estudantes, artistas, professoras, jornalistas, comerciárias, bancárias, telefonistas, domésticas, camponesas, costureiras, funcionárias, mulheres que trabalham em todos os setores. Lutemos unidas pelos nossos direitos, por melhores salários e ordenados, pelo nosso direito de viver ${ }^{\mathrm{iv}}$.

Com participação significativa na composição do movimento operário, as mulheres também se aglutinaram no interior dos partidos políticos, mesmo que parte da historiografia não tenha atestado. Os indivíduos que compunham os quadros do Partido Comunista do Brasil ao realizarem o trabalho de rememoração de sua própria trajetória política e, principalmente, da trajetória do PCB, silenciaram personagens femininos de importante atuação. Em decorrência, o reconhecimento da militância feminina no interior do Partido Comunista do Brasil se deu de forma controversa, devido ao fato de a história do PCB, escrita pelos militantes que o integravam, ter sido organizada de modo a ignorar o papel da militância feminina junto ao mesmo.

Apesar de ser fato indiscutível que o partido bolchevique e as orientações soviéticas tenham sido grandes norteadores do Partido Comunista do Brasil, há certas discordâncias na historiografia do PCB acerca do total cumprimento dos direcionamentos propostos pela Internacional Comunista por este. Alguns autores afirmam não se poder asseverar que tenham sido seguidas e aplicadas indistintamente à realidade nacional, sendo a Internacional apenas auxiliadora da organização dos partidos comunistas e não uma organização de fundamental poder decisório, pois acredita-se que o PCB possuía total autonomia e responsabilidade sobre o movimento operário brasileiro e se orientava em função da sua realidade, a exemplo de Leandro Konder (1988).

Em contrapartida, Edgar Carone, em seus estudos, aponta para a ideia de total consonância entre o PCB e a Internacional Comunista, pois "a ligação prende-o a um modelo que aparece delineado em todos os sentidos, desde a filiação ideológica até seu arcabouço organizatório" (1989, p.94). Na mesma linha, Dulce Pandolfi assinala que "o fato de ser membro da Internacional Comunista não tinha uma importância meramente formal, para o PCB. Muitas foram as implicações daí decorrentes. Sobretudo do ponto de vista ideológico, a presença da Internacional marcou profundamente a história dos comunistas brasileiros" (1995, p. 74).

O modelo construído pela III Internacional foi adotado de forma "unívoca e universal" por todos os agrupamentos comunistas, inclusive pelo PCB. Ao buscar se diferenciar da 


\section{O PARTIDO COMUNISTA DO BRASIL E A MILITÂNCIA \\ FEMININA}

anterior, a III Internacional apregoava o rompimento com o reformismo visto como contrário à revolução e a modificação inevitável da ordem econômica, social e política do capitalismo. Para Pandolfi, esse paradigma "teve consequências profundas na condução do movimento comunista internacional, determinando, inclusive, uma nova concepção de partido político. Sem dúvida, ele marcou também toda a trajetória do PCB” (PANDOLFI, 1995, p. 56).

Embora as várias divergências dos estudos sobre o Partido Comunista do Brasil quanto a sua relação com a Internacional Comunista não leve a um ponto comum de interpretação, é possível assegurar a forte influência desta tanto na organização quanto na formação teóricoideológica do partido brasileiro. As diretrizes propostas pela Internacional nos auxiliam na compreensão das bases que fundamentaram a criação e o desenvolvimento do PCB, mesmo que tal relação não tenha se mantido estática sofrendo, em dado momento, modificações significativas como, por exemplo, seu acirramento nos anos de 1930 e 1950:

O início da década de 1930 pode ser considerado como um momento de
recrudescimento da relação entre a seção brasileira e a Internacional
Comunista. Seus principais militantes e intelectuais são afastados pela prática
da "proletarização" e do "obreirismo" [...] A década de 1950 apresenta um
momento marcante da relação entre os militantes pecebistas e a orientações
do partido soviético [...]. O Partido Comunista do Brasil não só passou a adotar
o pensamento stalinista, codificado na formulação marxismo-leninismo, como
perspectiva, mas também a organizar-se internamente como vetor as
orientações soviéticas. (OLIVEIRA, 2016, p. 35).

A relação estabelecida entre o PCB e as diretrizes propostas pela Internacional Comunista nos são importantes para além da compreensão de como aquele se estruturou. É essencial aqui perceber como estavam sendo geridas as questões relacionadas à mulher pela $\mathrm{IC}^{\mathrm{v}}$ e qual sua ressonância no Partido Comunista do Brasil. A importância da participação das mulheres no movimento operário, bem como a discussão sobre a sua condição, já haviam sido tratadas por August Bebel exaustivamente no interior do Partido Social-Democrata Alemão ${ }^{\text {vi }}$. Contrariando grande parcela do partido, Bebel teve suas ideias rechaçadas por outros dirigentes companheiros, mas ainda assim sua obra A mulher e o socialismo (1879) foi largamente difundida.

Nos primeiros anos após a Revolução Russa muito se discutia sobre mecanismos de atuação junto ao contingente de mulheres trabalhadoras. O partido soviético tinha em mente a cooptação das massas femininas em favor da causa operária para que não as perdessem aos contrarrevolucionários e nem ao movimento feminista burguês. Em diálogo com Lênin ${ }^{\text {vii }}$, Clara 


\section{O PARTIDO COMUNISTA DO BRASIL E A MILITÂNCIA FEMININA}

Zetkin - importante militante comunista que se destacou na luta pela causa das mulheres ${ }^{\text {viii }}$ discutiu sobre a urgência em se tratar da questão feminina. Em suas falas, é possível perceber a importância atribuída às organizações de mulheres como parte integrante e fundamental para a consolidação do movimento operário. Segundo Lênin, as mulheres realizavam um trabalho incessante no partido, eram incansáveis, fiéis e inteligentes, no entanto, não se tinha um movimento comunista internacional das mulheres e por isso havia a necessidade urgente em cria-lo. Ao partido, segundo ele, cabia a elaboração de um plano de trabalho junto a elas, a criação de comitês e órgãos nos quais estivessem incluídas e assim conseguissem se mobilizar e melhor se organizar em prol da causa comunista:

Uma comunista é um membro do partido com os mesmos deveres e direitos que os seus camaradas masculinos. Nisto não pode haver quais quer divergências. No entanto, não podemos fechar os olhos perante os factos. $\mathrm{O}$ partido deve ter órgãos, grupos de trabalho, comissões, comités, secções, ou como lhe queiram chamar, cuja tarefa específica consistirá em despertar as amplas massas de mulheres, ligá-las ao partido e mantê-las sob a sua influência. Para isso, naturalmente, é necessário que desenvolvamos um trabalho verdadeiramente sistemático junto destas massas de mulheres. Devemos educar as mulheres que saíram da passividade, recrutá-las e armálas para a luta proletária de classe sob a direcção do Partido Comunista. Penso não só nas proletárias que trabalham nas fábricas ou se ocupam do trabalho doméstico, mas também nas camponesas, nas mulheres das diversas camadas da pequena burguesia. Todas elas são também vítimas do capitalismo, e desde a guerra são-no mais que nunca. A mentalidade atrasada, apolítica, a-social dessas mulheres, a estreiteza do seu campo de actividade, todo o seu modo de vida - estes são os factos. Seria absurdo, totalmente absurdo não termos isto em atenção. Precisamos de ter os nossos organismos para o trabalho junto das mulheres, métodos de agitação e formas de organização específicos (LÊNIN apud ZETKIN, 2015, p.11).

Lênin não perdeu de vista as especificidades inerentes à condição feminina, sua opressão em detrimento dos privilégios masculinos e sua submissão de todas as formas na sociedade de classes, apelando "às mulheres, de igual para igual, a trabalharem elas próprias na transformação da economia e da superestrutura ideológica” (LÊNIN apud ZETKIN, 2015, p.12). Contudo, deixa claro que a causa feminina em nada poderia se dissociar do fim maior, a Revolução, este era o principal horizonte ao qual homens e mulheres deveriam vislumbrar.

Tal posicionamento não se dava de forma homogênea no interior do partido, havendo reações contrárias a este modo de organização e expressão das mulheres, as quais eram rotuladas como "oportunismo, traição e abandono dos princípios", como discorre Clara Zetkin: 
Disse a Lénine que os seus argumentos eram para mim um apoio precioso. Muitos camaradas, bons camaradas, tinham-se oposto resolutamente a que o partido criasse organismos específicos para o trabalho regular junto das amplas massas de mulheres. Declararam que isso era o regresso às tradições sociais-democratas e à famigerada "emancipação da mulher". [...] Assegurei a Lénine que partilhava o seu ponto de vista, mas que enfrentaria indubitavelmente muita resistência. As mentes hesitantes e temerosas iriam rejeitá-lo como um "oportunismo perigoso". E não se podia negar que também as nossas reivindicações actuais a favor das mulheres podiam ser mal compreendidas e interpretadas (LÊNIN apud ZETKIN, 2015, p.12-13).

Ambos salientam os avanços na Rússia Soviética quanto a discussão das questões femininas, bem como as iniciativas de organização e atividades que pudessem ser regularmente desenvolvidas pelas mulheres militantes, mas ainda insuficientes, por se tratar de uma conduta, de certo modo, "passiva e expectante face ao problema da criação de um movimento de massas de mulheres trabalhadoras". Assim, era urgente a necessidade de se aprimorar e expandir as ações de incentivo a militância das mulheres, tornando as conferências e congressos nacionais em internacionais que, por meio de um maior alcance, possibilitaria as massas femininas dos países capitalistas a tomarem consciência da causa comunista e de sua própria condição.

As ideias aqui expostas por meio do diálogo entre Clara Zetkin e Lênin foram sistematizadas e serviram de norte para as Teses sobre métodos e formas de trabalho do Partido Comunista entre as mulheres, nos países soviéticos, atrasados e capitalistas, apresentadas no III Congresso da Internacional Comunista, realizado em Moscou, em 1921, em sua 20 a sessão (SOIHET, 2013, p. 190). As resoluções da III Internacional Comunista se direcionavam somente a formação de organizações femininas no sentido de preparar e mobilizar a massa de mulheres operárias para a revolução socialista. Para Zetkin, as questões que diziam respeito as especificidades das lutas feministas deveriam estar submetidas à tarefa mais emergente da causa socialista.

O princípio guia deve ser o seguinte: nenhuma agitação especificamente feminista senão agitação socialista entre as mulheres. Não devemos pôr em primeiro plano os interesses mais mesquinhos do mundo da mulher: nossa tarefa é a conquista da mulher proletária para a luta de classes (ZETKIN, 1976, p.107).

Rachel Soihet esclarece que os partidos comunistas pouco haviam avançado em relação a uma elaboração teórica sobre a condição feminina de fato, salvo o caso do Partido Comunista Italiano, sob a liderança de Palmiro Togliatti, de 1945 a 1970. Segundo a autora, "pela primeira vez, um dirigente político disse à mulher que ela não deveria continuar a se sacrificar, a sofrer em silêncio pelo bem da pátria, como, aliás, sempre fez, mas que para o bem da pátria ela 


\section{O PARTIDO COMUNISTA DO BRASIL E A MILITÂNCIA FEMININA}

deveria falar, agir, lutar por seus direitos" (SOIHET, 2013, p. 190). Ao expor que a superação da sociedade capitalista era insuficiente à libertação da mulher, assim como sua inserção na produção, que seria preciso mais que isso para uma mudança sistemática, Togliatti não teve suas ideias recebidas com entusiasmo pela URSS.

Soihet, em entrevista com Zuleika Alambert, militante comunista que se dedicou a causa feminina e muito se empenhou na denúncia da subvalorização da mulher pelos partidos e organizações de esquerda tecendo, inclusive, várias críticas ao PCB, expõe que esta, ao discorrer sobre sua experiência na União Soviética durante os anos de exílio,

afirma que os soviéticos não enfrentavam as questões relativas à especificidade feminina, alegando "que a mulher participou da revolução ao lado dos homens, trabalha e estuda como eles, e que, portanto, não há mais nada a reivindicar". Fato com o qual não concordava, já que embora a mulher fosse valorizada legalmente, havia toda uma questão cultural que impedia de fato uma situação igualitária entre mulheres e homens (SOIHET, 2013, p.191).

O partido soviético, assim como os demais partidos comunistas, apesar dos esforços em inserir na pauta de discussão o trabalho junto às mulheres operárias e militantes, ainda encontrava forte resistência em seu interior em avançar nas medidas de intervenção junto a estas e, principalmente, de promover mudanças substanciais no que tange às especificidades femininas e sua condição de subvalorização.

As diretrizes propostas pela III Internacional, no que diz respeito ao trabalho junto às mulheres, foram largamente difundidas a fim de que os partidos comunistas, de todas as localidades, colocassem-nas em prática. O Partido Comunista do Brasil promoveu a criação de diversas organizações especificas para as mulheres ${ }^{\text {ix }}$, de acordo com as concepções propostas pela III IC, como, por exemplo, a União Feminina do Brasil (UFB), criada em 1934, ligada a Aliança Nacional Libertadora (ANL). Tal associação, assim como outras que surgiram posteriormente $^{\mathrm{x}}$, estavam ligadas ao partido muitas vezes de forma implícita e não possuíam intenção de uma incorporação maior das causas especificas das mulheres, denotando o desejo apenas de atrai-las ao movimento operário e alargar as suas fileiras. Tal fato é salientado por Iracema Ribeiro durante sua intervenção no IV Congresso do PCB, em novembro de 1954:

$\mathrm{O}$ trabalho do nosso Partido entre as mulheres apresenta serias debilidades. $\mathrm{O}$ sectarismo é o principal entrave ao trabalho do Partido junto às massas femininas. As próprias Organizações de Base femininas criadas para facilitar o trabalho do Partido junto às grandes massas de mulheres, não têm cumprido satisfatoriamente sua missão. Em sua maioria as Organizações de Base 
femininas realizam mais o trabalho de agitação e propaganda, deixando de lado a tarefa fundamental para a qual foram criadas, isto é, mobilizar e organizar as mulheres partindo das suas reivindicações específicas, das lutas contra a carestia, pelo congelamento de preços, em defesa da infância e elevando-as até às lutas democráticas e emancipadoras ${ }^{\mathrm{xi}}$.

Percebe-se que as chamadas "reivindicações específicas" a que as mulheres estavam atreladas se convertem na luta pela carestia ou na defesa da infância, como se tais questões não dissessem respeito ao universo masculino também. No que se refere a marginalização da mulher e a subvalorização do seu trabalho nada é salientando. Ao ter como objetivo maior a construção de um partido de massas, os militantes do PCB entendiam a participação feminina e sua militância de forma limitada e pontual.

Precisamos ter em cada organismo do Partido, desde as células até o Secretariado Nacional, encarregados especiais do movimento feminino. Além disso, precisamos procurar as causas verdadeiras da afluência ainda pequena de mulheres às fileiras de nosso Partido a fim de conseguir removê-las definitivamente. É indispensável fazer em cada organismo do Partido acurado estudo das condições em que vive a mulher, dos obstáculos que representam suas pesadíssimas tarefas domésticas à possibilidade de qualquer atividade nas fileiras de nosso Partido, de maneira a reduzir ao mínimo possível as exigências estatutárias para que a mulher possa ser militante comunista, possa progredir politicamente como ativista de nosso Partido sem prejudicar suas tarefas domésticas ${ }^{\mathrm{xii}}$.

O documento, de autoria de Luiz Carlos Prestes, a maior liderança do Partido, traz como ponto central a preocupação em atrair as mulheres para o interior do partido, expressando amplo desconhecimento e falta de compreensão substancial da problemática feminina e das causas que as distanciavam do movimento operário e da participação no partido. Há de se notar também que ao se referir às organizações femininas, aponta a necessidade de indicação de homens, “encarregados especiais”, cuja incumbência seria lidar e estudar a questão das mulheres.

$\mathrm{O}$ assunto sobre o trabalho doméstico permeia grande parte das diretrizes do partido no tocante às mulheres, diversas vezes, no período em que o PCB ainda se encontrava na ilegalidade, era proposto as militantes que, ao se filiarem, deveriam se dedicar integralmente ao partido, sendo essa uma forma de mantê-las afastadas das ocupações centrais e até mesmo da própria filiação pois era impossível a abdicação dos cuidados do lar (BERNARDES, 1995). Além do mais, a compreensão de que as tarefas domésticas eram competência exclusiva das mulheres denota que os próprios militantes e dirigentes do Partido Comunista careciam de outra concepção sobre a questão feminina. O relato de Auxiliadora Bambirra, ao expor a dificuldade 


\section{O PARTIDO COMUNISTA DO BRASIL E A MILITÂNCIA FEMININA}

que era competir com o seu esposo militante em razão das demandas domésticas, revela como a submissão da mulher em relação ao homem, mesmo o militante, estava arraigado no pensamento deste:

O Bambirra [Sinval Bambirra, marido de Auxiliadora], por exemplo, na época que eu comecei, ele dizia “... não gosto que você fique atuando nessa frente com as mulheres porque os dois não podem queimar... A gente não pode queimar porque um tem que ficar tomando conta das crianças. É bom que você reduza um pouco essas suas saídas". Quer dizer, de certa maneira, ele queria determinar, limitar minha atuação, mais em função da educação das crianças, que eram pequenas. Mas, ao mesmo tempo, ele não podia proibiriii.

A ideia de que o trabalho doméstico estava destinado às mulheres e a ele deveriam se dedicar prioritariamente, encontrava respaldo no interior do PCB, denunciando os limites do Partido no tratamento da questão. Em outras palavras, apesar das pretensões de se converter a ordem social em igualitária, onde vigorassem ideais emancipatórios, o feminino se manteve associado aos cuidados com o lar, a maternidade e o matrimônio. Ao que parece, fomentavam um discurso no interior da organização que historicamente vinha sendo disseminado. Mesmo após sua inserção no PCB, lhes eram atribuídas, muitas vezes, tarefas consideradas "femininas", voltadas ao assistencialismo e ao pragmatismo.

Com efeito, a estrutura organizativa do Partido Comunista do Brasil foi construída de forma hierarquizada e às mulheres não eram delegadas funções de alto poder decisório. Há relatos de algumas delas afirmando não saberem como se procediam as tomadas de decisões, tendo em vista que a sua participação era muitas vezes fora da estrutura partidária, desempenhando funções de apoio e auxílio, sem nunca ocupar cargos de maior destaque. Zuleika Alambert, primeira mulher a participar do Comitê Central do Partido Comunista do Brasil, desde o ano de 1947, "posição inacessível para a maioria das militantes" (SOIHET, 2013, p.172), teceu diversas críticas contundentes a forma como o partido lidava com as mulheres militantes.

O machismo imperava, e isto aparecia, nitidamente, na divisão dos trabalhos. As mulheres atuavam como datilógrafas, taquígrafas nas reuniões do Partido. Serviam cafés, cozinhavam, limpavam os chamados 'aparelhos'. Nas comissões políticas de trabalho eram geralmente eleitas para as comissões gerais, ou seja, aquelas onde cabia de tudo. Para representar o Partido nos Congressos Internacionais jamais eram eleitas e assim por diante ${ }^{\mathrm{xiv}}$

Ainda sobre a acentuada diferença entre os trabalhos designados a homens e mulheres no interior do partido, Alambert em seu retorno do exílio - onde teve contato mais profundo com o movimento de mulheres europeu, o que lhe proporcionou uma maior percepção da reprodução 


\section{O PARTIDO COMUNISTA DO BRASIL E A MILITÂNCIA FEMININA}

de valores machistas no interior das organizações de esquerda - declarou ao Jornal da República:

Na verdade, era tratada como um homem no partido, atingira uma posição de homem, não era vista como uma mulher, pois o machismo é também muito forte dentro do partido. Os homens trazem toda a carga com que foram educados. É necessário um debate muito duro para mudar sua cabeça ${ }^{\mathrm{xv}}$.

É possível perceber, através dos estudos realizados por Albertina de Oliveira Costa (1980) sobre a memória das mulheres militantes exiladas, nos quais registra diversos depoimentos, entre eles de militantes pecebistas, que, para boa parte delas, a percepção da relação de subordinação no interior do partido e das organizações só se tornou clara após o exílio, onde tiveram contato direto com os ideais de um feminismo amadurecido que lhes proporcionou uma crítica incisiva a respeito da militância no Brasil.

Se faz importante salientar também que as práticas de subvalorização e marginalização da mulher no seio das organizações de esquerda e no Partido Comunista do Brasil, não era uma particularidade da esquerda brasileira. Depoimentos de mulheres militantes de vários países como França, Estados Unidos, dentre outros, confirmam a existência de tais práticas nas organizações que integravam. A exemplo, o depoimento de uma militante francesa:

As mulheres dentro disso não tinham até agora senão duas possibilidades: brincar de secretárias ou se virilizar. Espontaneamente, propõem-se sempre aos militantes homens tarefas que exigem uma responsabilidade, um esforço de criação, uma tomada de posição pessoal: espontaneamente deixa-se sempre para as mulheres as tarefas mecânicas, só exigindo conhecimentos técnicos como mimeografar os folhetos, bater à máquina, ocupar-se das finanças, etc. (DURAND apud ABREU, 2010, p. 77).

Assunto bastante controverso ao se analisar as relações estabelecidas no interior do Partido Comunista do Brasil, comumente chamados de "tática dois", diz respeito aos fatos relatados por alguns militantes. Se tratava de delegar a militantes mulheres a tarefa de conseguir favores ou informações por meio de atividades sexuais. Salientam que tal atividade era muitas vezes realizada, mesmo que dificilmente admitida por seus companheiros de partido. Patrícia Galvão, mais conhecida como Pagu, importante militante da causa operária e em favor da emancipação e liberdade feminina, foi uma das mulheres que sofreu esse tipo de imposição dos seus próprios companheiros de partido: 
Estou de acordo com o sacrifício total, se se tratasse de uma coisa que valesse a pena, se se tratasse de vidas, num momento de luta armada, em plena revolução. Mas assim, para obter ridículas informações, que nem sequer se sabe se serão aproveitadas, eu acho que é exigir demais das mulheres revolucionárias. Eu não sou prostituta. [...] Pensam que uma aventura a mais ou a menos para mim não tem importância nenhuma. Uma mulher de pernas abertas: é o que vocês pensam (GALVÃO apud FERRAZ, 2005, p. 126).

Patrícia Galvão tece críticas contundentes ao discurso disseminado no partido por homens que deturpavam, ao mesmo tempo que se auto justificavam, os ideais de emancipação e liberdade do próprio corpo defendido por muitas companheiras.

Por defenderem tais ideais, as mulheres estavam sujeitas a todo tipo de comportamento dos homens, fora e dentro do partido, que se achavam no direito de transpor qualquer limite. Patrícia Galvão relata, deixando claro sua repulsa, o comportamento de um companheiro de partido que tenta se impor a ela através de investidas sexuais: "Como era revoltante e ridículo despir a capa comunista. Que nojo ao vê-lo atirar-se a minha procura com a vulgaridade brutal e desastrada que eu já conhecia nos homens de outras classes sociais" (GALVÃO apud FERRAZ, 2005, p. 87).

Dada a forma como se estabeleceram as relações entre homens e mulheres no Partido Comunista do Brasil, como se deram as interações cotidianas e os lugares ocupados por um e por outro na estrutura partidária, é possível analisar como as construções sociais se manifestaram nessas relações e como ali se estabeleceram as relações de gênero. Através dos relatos expostos, é possível notar ainda como a prática política dos militantes ligados ao PCB, no tocante à mulher, se encontrava imbuída de concepções difundidas pela sociedade capitalista patriarcal, reforçando a reprodução de valores acerca da marginalização e da subvalorização femininas, de forma a contrastar com os ideais comunistas racionalmente elaborados.

Entendemos gênero a partir das formulações de Joan Scott, para quem "gênero é um elemento constitutivo das relações sociais, baseadas nas diferenças percebidas entre os sexos e mais, o gênero é uma forma primeira de dar significado às relações de poder" (1995, p. 21). Em consonância com a autora, inferimos que homens e mulheres estão inseridos em uma realidade histórica e são produtos do meio social, não podendo perder de vista a natureza relacional entre os sexos, de modo que homens e mulheres sejam vistos em suas múltiplas conexões, suas hierarquias e relações de poder.

Nessa perspectiva, analisamos como a sociedade capitalista patriarcal se constituiu tendo como base as relações de poder a partir do sexo para a determinação dos lugares 


\section{O PARTIDO COMUNISTA DO BRASIL E A MILITÂNCIA FEMININA}

destinados a homens e mulheres, e assim relegou a estas posições marginais e de valor menor, em detrimento da posição de superioridade daqueles, em todas as esferas sociais. Estando o Partido Comunista do Brasil inserido nesta realidade, reproduziu tais valores e concepções, fomentando uma identidade do feminino e do masculino, que os aloca em determinadas funções e estabelece graus de importância.

O PCB se movia em uma sociedade capitalista, mesmo que seus posicionamentos se estabelecessem de modo contrário a essa estrutura e a favor de uma mudança social do modo de produção vigente. Tal sociedade, como foi explicitado, tinha como pressupostos, no tocante á mulher, sua marginalização e subvalorização. Assim sendo, o partido carregou consigo muitas dessas concepções, visíveis na forma de estruturação dos seus quadros, da participação das mulheres internamente, nos discursos proferidos e na maneira como procuraram lidar com as questões femininas de modo geral.

\section{A Memória do PCB e o silenciamento sobre a militância feminina}

Através de uma abordagem que privilegia a interdisciplinaridade da memória, buscamos compreender de que forma se deu os processos mnemônicos a que estão sujeitos os indivíduos como unos e em sua coletividade, na tentativa de responder a partir de que lugar e de que marcos sociais da memória (HALBWACHS, 2004) os militantes do Partido Comunista do Brasil se lembram das mulheres como sujeitos militantes, e assim entender, por outro lado, o esquecimento a que foram submetidas.

Na tentativa de avançar na abordagem da memória trazida por Halbwachs (2004), consideramos a questão das fissuras nos grupos, observando para além da coesão, ponto chave na obra do autor. A compreensão de que "toda dinâmica processual decorrente das disputas ocorridas no palco social da hegemonia da memória, ou seja, as lutas pela dominação, os conflitos, os interesses antagônicos subjacentes à construção social do passado, que está ausente da análise de Halbwachs" (PERALTA, 2007, P. 06), nos será de extrema importância, sob a finalidade de responder aos questionamentos direcionados á historiografia do Partido Comunista do Brasil, escrita pelos militantes que o integrava, à medida que estes, durante o processo de rememoração da formação do partido e sua trajetória, relegaram ao esquecimento a participação feminina. 


\section{O PARTIDO COMUNISTA DO BRASIL E A MILITÂNCIA FEMININA}

Halbwachs, (2004) ao designar que o passado é rememorado no interior das instituições, seja religiosa, familiar, classe social, seja os grupos políticos aos quais os indivíduos pertencem, parte da premissa que é na sociedade onde os indivíduos "recordam, reconhecem e localizam suas memórias". Possibilita-nos com isso entender que há certa sujeição das memórias individuais ao coletivo, já que, as lembranças são sempre provenientes deste processo, tendo a proximidade afetiva ao grupo, ou podemos dizer também, o sentimento de identidade, de pertença, valor substancial na consistência dessas lembranças, pois "se nossa impressão pode apoiar-se não somente sobre nossa lembrança, mas também sobre a dos outros, nossa confiança na exatidão de nossa evocação será maior” (HALBWACHS, 2004, p.25).

Portanto, segundo Maurice Halbwachs, o grupo fornece ao indivíduo quadros em que este ancora suas lembranças e são a partir destes quadros que o indivíduo é capaz de reelaborar o passado a partir do presente, não só subordinado pelas necessidades que este demanda, como também através de instrumentos internos de que os quadros sociais dispõem: "cuando recordamos, partimos del presente, del sistema de ideas generales que está siempre a nuestro alcance, del linguagem y de los puntos de referencia adoptados por la sociedad, es decir de todos los medios de expresión que pone a nuestra disposición" (HALBWACHS, 2004, p. 41).

Em conformidade com tal análise, consideramos o Partido Comunista do Brasil o quadro fundamental para a rememoração dos indivíduos que a ele se atrelaram e escreveram sua história. Concebemos, através da compreensão sobre marcos sociais da memória, a marginalização e a subvalorização das mulheres militantes vigentes no interior do partido, expressão e reprodução da sociedade capitalista, como valores, concepções e práticas a partir das quais os militantes elaboraram suas memórias sobre a construção do PCB e sua trajetória política, e assim escreveram as obras que vieram a compor a história do Partido Comunista do Brasil, na qual não reconheceram a participação das muitas mulheres que militaram ao lado deles.

Os conflitos existentes no interior dos grupos e as disputas políticas pela conservação da memória são pontos essenciais das formulações desenvolvidas por Michael Pollak (1989; 1992). Ampliando as análises formuladas por Halbwachs, o teórico contribui na pesquisa quando parte da premissa que a memória é um fenômeno construído, sujeito a um processo seletivo onde os atores sociais, indivíduos, grupos ou instituições, elegem de acordo com designíos pessoais ou políticos o que deverá, no processo de rememoração, ser incluído ou 


\section{O PARTIDO COMUNISTA DO BRASIL E A MILITÂNCIA FEMININA}

delimitado, podendo este ser um trabalho de organização consciente ou não, como é salientado pelo autor:

quando falo em construção, em nível individual, quero dizer que os modos de construção podem tanto ser conscientes como inconscientes. O que a memória individual grava, recalca, exclui, relembra, é evidentemente o resultado de um verdadeiro trabalho de organização (POLLAK, 1992, p.204).

Para tanto, há que se levar em consideração as relações que se estabelecem no interior dos grupos e de que forma os indivíduos neles transitam, pois, estando a memória sujeita a um processo de construção, permeado por interesses e conflitos, é necessário apreender quem são os agentes responsáveis por sua elaboração.

Partindo da premissa que a produção do conhecimento, sua expressão e reprodução estão atravessadas tanto pelos processos da memória quanto pelas relações sociais e políticas, nos cabe demonstrar que a construção da memória acerca do Partido Comunista do Brasil não se deu de forma autonomamente coletiva. É possível admitir que a memória está inserida nas relações de poder que se manifestavam no interior do partido, tendo aqueles que se configuravam como seus "guardiões" ou "senhores" o privilégio de eleger o que seria dito ou não, deste modo, os silêncios e esquecimentos se tornam reveladores.

\section{CONCLUSÃO}

Tratar do silenciamento que cobre as militantes do Partido Comunista do Brasil, é também tratar da memória, a entendendo como um fenômeno dinâmico e interativo que se insere e é resultante de complexas relações sociais, considerando que lembrar e esquecer implicam em movimentos de um mesmo processo. Por meio da problematização da memória se faz possível investigar acerca dos processos e motivações que levaram ao silenciamento acerca da participação das mulheres pelos militantes do PCB ao escreverem suas obras, que viriam a compor inicialmente a história oficial do partido.

Ademais, constata-se que nas lutas empreendidas por aquele que durante muito tempo foi o principal partido vinculado ao movimento operário, o tratamento relativo à condição feminina, dentro e fora do partido, evidencia os valores ainda vigentes na sociedade capitalista patriarcal e que se configuraram como fatores influentes na produção das obras que vieram a compor a história do Partido e demarcaram a memória e a história deste, relegando ao esquecimento as mulheres militantes. Entendemos que refletir sobre tais questões é 
fundamental para uma melhor compreensão sobre as lutas pela construção de uma sociedade mais igualitária e mais humana no passado e na contemporaneidade.

\section{NOTAS}

${ }^{\mathrm{i}}$ O presente artigo é resultado de uma pesquisa mais ampla desenvolvida durante o Curso de Mestrado no Programa de Memória: Linguagem e Sociedade, da Universidade do Sudoeste da Bahia da UESB.

ii O Partido Comunista do Brasil foi criado oficialmente em 25 de março de 1922, na cidade de Niterói, no Rio de Janeiro, como Seção Brasileira da Internacional Comunista. Todavia, pouco tempo depois entra na ilegalidade, alternando alguns poucos períodos de atuação legal. Em 1961, em meio às alterações políticas ocorridas na URSS, em Cuba e as divergências internas entre os militantes, o nome do partido foi alterado para Partido Comunista Brasileiro. Contudo, a sigla PCB permaneceu. Neste trabalho, a análise refere-se exclusivamente ao Partido Comunista do Brasil entre os anos de 1922 e 1961.

iii Entre outros estão: ALVES, 2013; TAVARES, 2011; SCHIMIDT, 2008; SILVA, 1996.

iv WERNECK, MARIA. Op. Cit. p. 41-42 apud ALVES, Iraceli da Cruz. A política no feminino: uma história das mulheres no Partido Comunista do Brasil - Seção Bahia (1942-1949). Feira de Santana, 2015.

${ }^{v}$ Abreviação de Internacional Comunista

${ }^{v i}$ Mais a respeito ver: ANDRADE, Joana El-Jaick. A mulher e o socialismo: incorporação da emancipação feminina à pauta da social democracia. Lutas Sociais, São Paulo, n.24, p.09-17, 2010.

vii $\mathrm{O}$ documento foi elaborado por Clara Zetkin relatando dois encontros que teve com Lênin, líder da Revolução Russa de1917, para tratar da questão feminina. O texto foi publicado originalmente em Moscou, em janeiro de 1925, sob o título Do meu livro de notas. O presente relato foi traduzido e publicado em diversos países, no Brasil foi inserido na coletânea $O$ Socialismo e a Emancipação da Mulher, Editorial Vitória, 1956, com o título "Lênin e o Movimento Feminino". Disponível em http://www. marxists.org/português/zetkin/1920/ mes/lenin.htm, em 22 de Maio de 2021.

viii Outras figuras femininas tiveram grande expressão como militantes do movimento revolucionário, dentre elas: Rosa Luxemburgo, Alexandra Kollontai e Nadejda Krupskaia, companheira de Lenin, dentre outras revolucionárias e teóricas do marxismo, cujas contribuições na luta contra a opressão do indivíduo na sociedade de classes são imensuráveis, assim como seus trabalhos de educação e conscientização em prol da emancipação feminina atrelada a um programa mais amplo de transformação integral da sociedade capitalista.

ix Houve também a criação do jornal Momento Feminino, em 1947, um órgão informativo dirigido por Arcelina Mochel, militante pecebista. Embora seguisse as orientações do PCB, não possuía vinculo oficial com o partido. LINS, Marcelo da Silva. As questões de gênero no interior do Partido Comunista do Brasil - PCB (1928-1947). Revista Temporalidades - Revista Discente do Programa de Pós-Graduação em História da UFMG. v. 7 n. 2 (mai./ago. 2015) Belo Horizonte: Departamento de História, FAFICH/UFMG, 2015.

${ }^{x}$ Sobre outras associações e suas formas de atuação ver: ALVES, Iraceli da Cruz, op. Cit.

xi RIBEIRO, Iracema. O trabalho feminino: dever de todo o Partido. In: Problemas Revista Mensal de Cultura Política, n.64, 1954. Disponível em https://www.marxists.org/portugues/tematica/rev_prob/64/feminino.htm em 22 de março de 2021.

xii Informe Político da Comissão Executiva ao Pleno do Comitê Nacional do PCB em 8 de dezembro de 1946. Texto presente em: PRESTES, Luiz Carlos. Problemas atuais da Democracia, Ed Vitoria, 1947. Disponível em https://www.marxists.org/portugues/prestes/1946/12/08.htm em 22 de março de 2021.

xiii Depoimento de Auxiliadora Bambirra à Magda de Almeida Neves - 14 de dezembro de 1993. Acervo do Programa de História Oral / UFMG. TAVARES, B. M. M. Gênero e política: a questão feminina no interior do PCB. Disponível em: www.ichs.ufop.ber/conifes/anais/MPC/mpc0401.htm em 22 de março de 2021

${ }^{\text {xiv }}$ Entrevista com Zuleika Alambert realizada por Maira Luísa Gonçalves de Abreu, em junho de 2004, via correspondência. ABREU, Maira Luisa Gonçalves de. Feminismo no exílio: o Círculo de Mulheres Brasileiras em Paris e o Grupo Latino-Americano de Mulheres em Paris - Campinas - SP, 2010.

xv "O machismo é forte no PCB, diz Zuleika" - Jornal República. Rio de Janeiro, 05 de novembro de 1979, № 60, Ano I. Disponível no acervo da Hemeroteca Digital Brasileira: http://bndigital.bn.br/acervo-digital/jornalrepublica/194018. 22 de março de 2021 


\section{REFERÊNCIAS}

ALVES, Iaracélli da Cruz. A política no feminino: uma história das mulheres no Partido Comunista do Brasil - Seção Bahia (1942-1949). Feira de Santana, 2015.

ANDRADE, Joana El-Jaick. A mulher e o socialismo: incorporação da emancipação feminina à pauta da social democracia. Lutas Sociais, São Paulo, n.24, p.09-17, 2010.

BAtalHA, Claudio Henrique de Morais. O movimento operário na Primeira República. Rio de Janeiro: Jorge Zahar Ed. 2000.

. A historiografia da classe operária no Brasil: trajetória tendências. In: FREITAS,

Marcos Cezar de. Historiografia Brasileira em perspectiva. São Paulo: Contexto, 1998, p. $145-158$.

BEBEL, Ferdnand August. A mulher e o socialismo. Alemanha, 1879. Capitulo 23

Disponível em <https://www.marxists.org/portugues/bebel/1879/mulher/28.htm> Acesso: 10 de maio de 2016.

BERGSON, Henri. Matéria e Memória: ensaio sobre a relação do corpo com o espírito. São Paulo: Martins Fortes, 1999.

BITTENCOURT, Ícaro. O operariado no Brasil da Primeira República: alguns apontamentos teórico-metodológicos e historiográficos. Revista Social e Humana, Santa Maria, v. 20, n. 01, jan/jun 2007, 141-151.

BRAGA, Elizabeth dos Santos. A constituição social da memória: uma perspectiva histórico-cultural. Ijuí - Rio Grande so Sul: Ed. Unijuí, 2000.

CARONE, Edgar. Classes sociais e movimento operário. São Paulo: Ática, 1989.

CHILCOTE, Ronald H. O Partido Comunista Brasileiro. Rio de Janeiro: Graal,

COSTA, Albertina. et. al. Memórias das mulheres do exílio. Rio de Janeiro: Paz e Terra, 1982.

COSTA, Albertina de Oliveira e BRUSCHINI, Cristina. Uma questão de gênero. Rio de Janeiro: Rosa dos Tempos; São Paulo: Fund ação Carlos Chagas, p. 289-309, 1992.

COLLING, Ana Maria. A construção do sujeito político mulher "subversiva". Contexto e Educação, Ijuí, v. 9, n. 35, p. 16-23, jul/set. 1994.

CUNHA, M. de F. Mulher e historiografia: da visibilidade à diferença. História e Ensino.

Revista do Laboratório de Ensino de História, v. 6, p. 141-161, 2000.

DEL PRIORE, M. A mulher na história do Brasil. São Paulo: Contexto, 1994.

. História das mulheres: as vozes do silêncio. In: FREITA, S. (Org.).

Historiografia brasileira em perspectiva. 4.ed. São Paulo: Contexto, 2001. p. 217-235.

DEL ROIO, Marcos. A classe operária na revolução burguesa: a política de alianças do PCB: 1928-1935. Belo Horizonte: Oficina de Livros, 1990. 


\section{FEMININA}

FALCÃO, Frederico José. Organizações Revolucionárias no Brasil: itinerários de integração à ordem. Rio de Janeiro: UFRJ/CFCHESCOLA de Serviço Social, 2010. Disponível em <http://www.cpihts.com/PDF05/Frederico\%20Falc\%C3\%A3o.pdf > em 08 de julho de 2016.

HALBWACHS, Maurice. A memória coletiva. Tradução: Laís Teles Benoir, São Paulo: Centauro, 2004.

HARDMAN, Francisco Foot. Nem pátria, nem patrão! Memória operária, cultura e literatura no Brasil. $3^{\text {a }}$ ed. São Paulo: UNESP, 2002.

HIRATA, Helena. KERGOAT, Daniéle. A Classe operária tem dois sexos. Revista Estudos Feministas. Rio de Janeiro, v.2, n.3, 1994.

KAREPOVS, Dainis. Luta Subterrânea: o PCB em 1937-1938. São Paulo, Hucitec. UNESP, 2003.

KONDER, Leandro. A derrota da dialética: a recepção das ideias de Marx no Brasil até o começo dos anos trinta. Rio de Janeiro: Campus, 1988.

LE GOFF, Jacques. História e Memória. 4ª ed. Campinas/SP: UNICAMP, 2003.

OLIVEIRA, Luan Eloy. Memória e História das Lutas Sociais no Brasil: um estudo sobre a obra de Everardo Dias (1962). Vitória da Conquista, 2015.

PANDOLFI, Dulce Chaves. Camaradas e Companheiros: memória e história do PCB. Rio de Janeiro: Relume-Dumará - Fundação Roberto Marinho, 1995.

PENA, Maria Valéria Junho. Mulheres e Trabalhadoras. Rio de Janeiro: Paz e Terra, 1981.

POLLAK, Michael. Memória, esquecimento, silêncio. In: Estudos Históricos, Rio de Janeiro: vol. 2, no 3, 1989. 1992;

. Memória e identidade social. In: Estudos Históricos, Rio de Janeiro, vol. 5, nº 10,

RICOEUR, Paul. A memória, a história, o esquecimento. Campinas - SP: Editora da Unicamp, 2007.

SAFFIOTI, Heleieth I. B. A mulher na sociedade de classes. São Paulo: Expressão Popular, 2013.

ZAIDAN FILHO, M. Construindo o PCB: 1922 - 1924. São Paulo: Livraria Editora Ciências Humanas, 1980. 